The Journal of Development and Administrative Studies, Vol. 22, No. 1-2, pp. 51-66, 2014

(c) CEDA/TU, 2000, US Library of Congress, Catlog Card No.: 79-915209, ISSN: 2091-0339

\title{
Retrospect and Prospect on Regional Industrial Policy in South Korea: The Case of Gwangju- Chonnam Region
}

\begin{abstract}
Sang-Ho Lee and Seung-Leul Kim*
Abstract

Gwangju-Chonnam region has long been recognized as an economically hollow region of South Korea. Even though there have been various kinds of policies and investments to vitalize its economy not only from central government, but also from local governments, its relative position in the country is not much changed. This paper is devoted to examine the industrial structure enhancement policies in Gwangju-Chonnam region in South Korea. First, we review the history of regional industrial policy implemented in Gwangju-Chonnam region, and present some policy considerations on regional economic innovation. Second, we classify regional policy directives by historical period, describe policy contents of each period, and discuss the limitations of regional policies adopted by the local governments, after pointing out important factors in selecting regional specialized industry by regions. Finally, under the economic environment faced with global trend of open competition, a brief policy recommendation is suggested in the conclusion.
\end{abstract}

Keywords: Regional industrial policy, industrial structure enhancement, regional specialized industry, global open competition.

JEL classification numbers: L16, L25, L38 and L39

\section{Introduction}

As the world economy is more integrated in the 21st century, global industrial structure has changed to global oligopoly in manufacturing industry, through international division of labor between developed and developing countries. And, global factors including rapid growth of developing countries such as China and India, the emergence of new growth engine industries such as informationcommunication technology and eco-technology, and intensified growth gap

Dr. Lee is a Professor of Economics and Dr. Kim is a post-doctoral researcher of Brain Korea-21 plus program, Department of Economics, Chonnam National University, 77 Yongbong-Ro, Bukgu, Gwangju, 500-757, South Korea.

Email of Corresponding author: Lee(sangho@jnu.ac.kr). 
between industries have had a significant impact on domestic industrial policies. As a response, regional governments in South Korea have continued to push ahead industrial policies to reorganize regional industrial structure in their regions. In particular, they have focused on new growth engine industry to promote regional economy by securing scientific technology capabilities.

Historically, in the meantime, national growth strategy of central government in South Korea has been continuously emphasized on the capital area, including Seoul-Gyeonggi region, and Southeast area, including Daegu-Gyongbuk region and Busan-Gyeongnam region. However, Gwangju-Chonnam region in Southwest area of Korean peninsula has been lag behind in the regional development process, which is illustrated by Figure 1. As the reasons for such economic backwardness, geographical conditions and political alienation are presented. First of all, from the perspective of geographical backgrounds, this region is appropriate for agriculture and fishery industry, which are relatively slowly developed in the process of industrial growth. Compared to other regions, this region consists of a vast plain area and archipelago. Thus, the location has unsuitable conditions for heavy chemical industry. In addition, coastline is longer than that of other regions, which is out of central route between Seoul and Busan for transporting the product to export foreign countries, such as Japan and USA, during development period. Consequently, when the central government of South Korea establishes main industrial facilities in the capital and Southeast areas, where pre-requisite infrastructures were already installed, Gwangju-Chonnam region was not equipped with natural conditions for heavy industry in implementing national economic development policies.

Figure 1. Regional Areas of South Korea

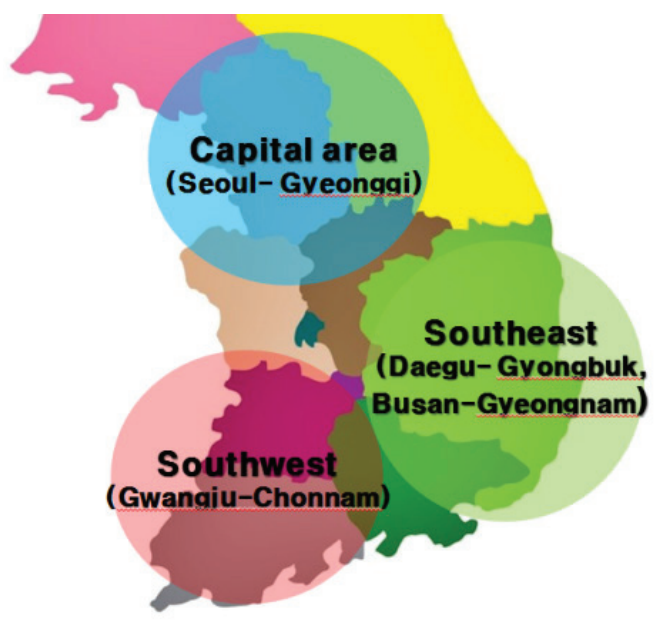


On the other hand, as for the political alienation, residents in Gwangju-Chonnam region themselves have pointed it as a main reason for economic backwardness. This view has emphasized that political regimes of the Southeast region have taken consecutive powers since 1960s, when national economic development policies were substantially initiated. The political power made this region being left with relative disadvantages in infrastructure and industrial distribution in the national level as well as in the private level in choosing the locations of companies. In fact, large scale industrial complex was constructed in major cities such as Daegu, Ulsan, Pohang in Gyeongbuk region and Busan, Masan, Changwon in Gyeongnam region in the Southeast area. This political background on the developmental regime sets the axis for transport in a way to connect the capital area to the Southeast area, which made Gwangju-Chonnam region being alienated from the main stream of national economic development.

However, it is fair to mention that Gwangju-Chonnam has received policy supports from the central government when local governments put some efforts to overcome the backwardness during development period. The central government implemented a regional development policy from 1975 to 1984 by introducing a loan from IBRD as a part of UNDP project, which was the first trial as a regional development policy by central government. In addition, there are various development policies presented by academic research, central government, and local governments. Although many of them are implemented after being adopted by each local governments, relative low-growth status of Gwangju-Chonnam region has not been improved. Why does it happen and how can we go forward to overcome this backwardness under increasing global competition? These are the questions and motivations what we have in mind.

The purpose of this research is to review the history of regional industrial policy, especially on the industrial structure enhancement policy, implemented in Gwangju-Chonnam region, and to present some policy considerations on regional economic innovation. Section II classifies regional policy directives by historical period and describes policy contents of each period. Section III discusses the limitations of regional policies adopted by the local governments, after pointing out important factors in selecting regional specialization industry by region. Finally, under an economic environment faced with global trend of open competition, a brief policy recommendation is presented as a conclusion.

\section{Retrospect on Regional Industrial Structure Enhancement Policy in Gwangju-Chonnam Region}

Industrial policy can be roughly divided into industrial structure policy, pursuing the enhancement of industrial structure, and industrial organization policy, securing 
fair competition in the industry. Korean industrial policy has been more emphasized on the former since 1960s. For example, industrial structure enhancement policy was implemented in 1962, based on national economic development plan. Later, promoting heavy chemical industry was a main part of the second and the third plan of the five-year national economic development plan. It represents that industrial structure enhancement policy was pushed ahead earlier by the active will of the central government.

However, Fair Trade Act as a foundation of industrial organization policy was established in 1982 and, even after its establishment; its role was more focused on the sanction of unfair actions rather than the structural change of monopoly market. Since the Asian financial (foreign currency) crisis in 1997, the direction of industrial policy has been shifted to industrial organization policy to promote market functions and fair competition.

On the other hand, it is simple that there is little interest in industrial organization policy in the regional government level. It is true that there is limitation in implementing regional industrial structure policy in the local level without considering the national framework on industrial structure. ${ }^{1}$ Thus, the regional development strategy of Gwangju-Chonnam region was within the extension of the national economic development plan. After the first economic development plan(1962-1967) in the national level was finished, research on development strategy of Gwangju-Chonnam region started around 1970s when the second national plan was implemented. Since the mid of 1970s, comparative study between regional economies, which were mainly about the nodal system targeting the development of regional society, has provided ways to enhance regional industrial structure. In the late 1980s, establishing industrial complex in GwangjuChonnam region and inducing companies to move into the region were emphasized as a way to overcome economic backwardness in Gwangju-Chonnam region. In the 2000 s, the efforts by the local governments were deployed to select regional specialized industry which is expected to lead regional development to overcome economic backwardness. As shown in table 1, the detailed history of the industrial policy for regional development in Gwangju-Chonnam region is described.

\footnotetext{
The central government in developed countries like the US and the UK has taken advantages of market functioning and stimulated economic activities in private sector by reinforcing regional economic environments, while the central government in developed countries like Japan and South Korea has used direct power on developing industry complex, selecting types of industry, and moving-in companies in the complex.(Sohn, 1997).
} 
Table 1. The history of the industrial policy for regional development in Gwangju-Chonnam region

\begin{tabular}{|l|l|}
\hline Periods & Policy Details \\
\hline Before 1975 & Beginning period of regional industrial structure policy \\
\hline From 1975 to 1985 & Period of regional development by central government \\
\hline From 1986 to 1997 & $\begin{array}{l}\text { Period of developing industrial complex and inducing } \\
\text { companies }\end{array}$ \\
\hline present since 1998 & Period of development strategy for high-tech industry \\
\hline
\end{tabular}

\section{Beginning period of regional industrial structure policy (Before 1975)}

After successful completion of the first 5-year national economic development plan by central government, discussion on regional industrial structure policy began in the late 1960s when the second national plan was ongoing. The early theory of regional development was more focused on social development, which covered social and cultural modernism rather than economic growth, with a theoretical background of Myrdal, Lewis, and Cherney. For example, Min(1970) examines basic strategies of regional economic development, classified national territories into advanced, growing, and sluggish areas. He then presentes basic direction of development strategy on the economic bloc of Gwangju-Chonnam region, as an example of the sluggish area. This research observes higher factor price in production and lower efficiency due to overpopulation in the advanced area, such as Seoul and Busan, which are intensively developed. It presumes that balanced regional development is reasonable for sustainable national growth and suggests the basic strategy of industrialization in the sluggish area. This study also suggests $\mathrm{d}$ the division of regions on the specializing industry with a higher index of specialization (LQ: Location Quotient) and the nodal system in accordance with the unbalanced growth theory. Specifically, it is emphasized that modernization of agricultural and fishery industries should be implemented through motorization, large-scale economies, and development of production process.

Min and Park (1974) present detailed development strategies by functioning and extended regional development strategy further. Emphasizing infrastructure building in substructure, they arrange several separated and different strategies on industrial functions, such as agriculture, fishery, tour, natural protection, island area, and ocean development. Looking into the industrial development strategy, for example, they considered nodal system and divide into the two upper bases, coastal industrial base and inland industrial base. Also they consider scale economies and place large-scale, middle-scale, and small-scale base for the two upper bases. Next,

2 See Min(1970), Park(1970), Min and Park(1974) for detailed data and in-depth analysis. 
after selecting location for each base, industries are listed to be specialized for the base. As for agriculture zone, for example, different core business on each division is presented after dividing into industrial agriculture zone in big city, commercial zone in urban area, and agricultural agriculture zone in food industry.

\section{Period of regional development by central government (1975-1985)}

Economic backwardness of Gwangju-Chonnam region, compared with capital and Southeast area, has been recognized since the late 1960s. The central government adopted unbalanced growth strategy in the first and second 5-year national economic development plan. Due to geographical advantage as a route for trade with Japan and the USA, Southeast area was intensively developed as an extension of the industrial policy in the Japanese colonial period, and as a result, perception on the relative backwardness of Gwangju-Chonnam region was widely spread.

However, national selection of industrial location according to the unbalanced development strategy resulted in over-population in the metropolitan areas(Seoul, Busan, and Daegu) and lower population in the rest area. As a result, balance in the national territory for national development was emerged as an urgent issue, which was later developed as a political issue. To mitigate the political pressure, central government accepted the first-phase report on regional development by UNDP and incorporated into the first total development plan of national land. In particular, in order to accept regional demands on the structural change to producing city from consuming city, Gwangju area was selected by central government for the targeted core area of regional development.

The regional development project of Gwangju-Chonnam region was aimed to develop intensively major city with the purpose of changing regional income level and promoting balanced regional development. It was expected that it would resolve overcrowded population in the metropolitan area and induce balanced development of the national territory. The main content can be summarized in the followings: building a base of food storage through large-scale development of agriculture in the riverside of Yeongsan river, industrial policy through construction of Yeocheon industrial complex and Gwangju industrial complex(Hanam), Suncheon agriculture distribution complex, access road construction(Dolsan large bridge, Jindo large bridge) into each complex area, urban development through residential district construction in Gwangju, Mokpo, and Yeosu, and projects (such as Yeosu fish-tank construction) to increase the income level of farmers and fishermen.

$3 \quad$ See Park(1984) and Cho(1985) for detailed analysis. 
The first phase started in 1975 and finished in 1980 along with the injection of the IBRD loan of 1,500 million USD. The second phase initiated in 1976, which was implemented in 1981 with the support of the IBRD loan of 6,500 million USD and finished in 1984. Attracting foreign investment into the development project of Gwangju-Chonnam region was evaluated successfully in the business unit level, achieving its goal for each unit. However, from the viewpoint of national growth, one-time project showed limitation in narrowing gap in regional incomes and changing the trend of rural exodus, as shown in less moving-in companies in the Hanam industrial complex, which was the central project toward producing city of Gwangju. The economic backwardness in Gwangju-Chonnam region remains as a continuous problem to be resolved constantly.

From this period, academic interests in regional specialized industry are emerged by using the index of LQ specialization and the index of comparative advantage. For example, Park(1984) analyzes the index of LQ and presents textile, clothes, leather, wood or wooden products, and non-metal mineral manufacturing as a specialized industry for Gwangju-Chonnam region. Considering the number of employees, fabricated metal and equipment manufacturing are added by the industry effect of the Asia automobile. In addition, printing business is added due to the role of Gwangju as a center city in administration and education. Also, he argues that high-tech industry should be promoted for pollution-free industrialization and thus, high-tech industry complex should be clustered to realize comparative advantages.

\section{Period of developing industrial complex and inducing companies $(1986-1997)^{4}$}

With holding the Olympic game and encountering the Uruguay Round, market opening and globalization were pushed ahead under the initiation of domestic municipality. The municipality started from a municipal election of local government in late 1990s. Thus, during the period, globalization and localization became national issues at the same time.

In 1987, Gwangju and Chonnam were separated each other, and they adopted a way to attract a company by developing an industrial complex within each jurisdiction as a regional development strategy to resolve the imbalance of regional economy and regionalism. The central government also avoided one-sided pushing way, such as government-led selection of the industrial complex in the national level, and shifted its way in supporting local governments' voluntary initiative.

4 See Jin(1990), Lee(1990, 1998), Lim(1993), SERI(1995, 1996), Sohn(1995, 1996) and Chung, et.al.(1998) for detailed data and in-depth analysis. 
Local governments had much interest in this policy because they could receive direct support from the central government if approved by the government after establishing a large-scale complex development project.

Gwangju established a development plan for high-tech industry complex and Pyeongdong industrial complex and Chonnam set a development plan for Daebul industrial complex and expansion of the Yeocheon industrial complex, respectively. Gwangju-Chonnam also cooperated to each other to get an approval from the central government. The regional industrial complex is substantially developed from this period. In case of Gwangju, following the first industrial complex in Hanam, the second and third complex in Hanam and the first and the second complex in Pyeongdeung were constructed as a part of a regional development project. In case of Chonnam, in addition to the complex in Mokpo and Suncheon, the first and second industrial complex were constructed in Munpyeong in Naju and Yulchon in Yeochoen along with Naju industrial complex, Yeongam Samho industrial complex, Gwangyang industrial complex, and Sypjin industrial complex. In the county level, land and social infrastructure were provided for businessmen by developing industrial and agriculture complexes to promote indigenous industry, residents' income improvement, and transition to the manufacturing-oriented structure.

On the other hand, while promoting manufacturing industry by facilitating land supply with constructing the industrial complex, development plans for newly highlighted industry were also presented. For example, as a responsive strategy toward the Uruguay Round, a movement of "one special product for each town" was implemented in a national level. Additionally, recognizing the importance of autonomous economic development along with municipality, wide-area local governments were eager to select a specialized industry as a strategy to achieve industrial structure enhancement.

The analytic method to select a specialized industry developed not only from adhering to LQ but to an input-output model, which considers forward and backward linkage effects and growth potential. Starting from 1990s, SERI(Samsung Economic Research Institute, 1995) published a result of study on the selection of regional specialized industry, based on the comparative research by region, and provided a service for a municipal corporation.

In 1996, in particular, SERI calculated linkage effect, based on the inter-industry relation (input-output) table in Gwangju-Chonnam region in 1988, and sorted specialized industry for each region using LQ, relative labor productivity analysis, unit labor cost analysis, and regional growth rate differential analysis. The specialized industries in Gwangju included food and groceries, tobacco, rubber, 
machine equipment, automobile and trailer, electric machine, etc, and those in Chonnam included the primary metal industry, petroleum refining, chemical products, non-metal mineral products, and rubber. According to the analysis of the report in 1994, there was no big change in the category in the case of Gawngju, though ranks of machine equipment, automobile and trailer outpaced food and groceries. It is notable that service industry such as finance, transport, and storage were added. Again, in the case of Chonnam, nothing is a noticeable change except that tour industry was added. However, from the comparison of regional production inducement coefficients, the specialized industries for Gwangju included beverage, textile and leather, the primary metal, construction transport and storage, public administration and defense industry, which were similar to selections in 1980 s along with the added industries such as service and public industry. The specialized industries for Chonnam included chemical products, petroleum refining, the primary metal, and utility (electricity/gas/water), which was similar to selections in earlier 1980s.

During the period, industrial complexes were constructed across the area as planned, but a moving-in rate was poor except for the Gwangju Hanam industrial complex. The moving-in rate was low even in Gwangju high-tech industrial complex and Daebul industrial complex, which were designated as a national industrial complex, and poor performance in the regional complex was worsen. Moreover, the advent of the financial (Asian foreign currency) crisis in the Korean economy in late 1997 exposed a hole of those complexes in development plan.

\section{Period of development strategy for high-tech industry (present since 1998)}

The financial crisis in the late 1997 provided a lesson that multiple factors should be reconsidered over the policy strategies pursued to date. Because of vacancies and withdrawal of moving-in in the industrial complex which were developed to provide land for plant and social infrastructure, necessary for business, the efforts to promote regional economic development stumbled and put the local governments under financial pressure. The Gwangju high-tech industrial complex and Daebul industrial complex, designated as a national industrial complex, were partly filled with apartments for the residential district but the rest remained empty. As a result, it is acknowledged that supplying complex is not enough for encouraging regional economy and only viable environments for profit can attract companies.

5 See Gwangju-Chonnam Developmet Institute(1998), Kang, et.al.(1999), Sohn(2000), Lee(2000, 2002) and Koo, et.al.(2011) for detailed data and in-depth analysis. 
Furthermore, digital economy emerges with the development of information technology that has fundamentally transformed the economic environment. Internet innovation shows that in addition to capital, labor, and land, information is essential as a source for competitiveness. In responding to this new economy, each country has made efforts to build information infrastructure like a high-speed network in national level, and local governments showed an interest in information technology and bio-industry. They started to establish a comprehensive inducement policy to promote venture industry under the market force.

In the case of Gwangju region, based on the long-term development plan established in 1998, information communication, electronics, bio-technology, healthcare service devices, new materials, optics, culture and convention industry, in addition to the existing general machine and transport machine, were presented as specialized industries in 2000s. More specifically, Gwangju city selected hightech part technology development, next-generation electric and electronic part material development, automobile part modulation business, and business for optical electronics clustering as strategic businesses for the region. In addition, some supplementary plans of promoting industrial design, building a base for EC/CALS and Internet business support center are presented as service industry to support the manufacturing industry. In particular, the optical electronics industry, with an approval of the support from central government, under a vision to build a position as a world leader in optical electronics industry after 2020, was intensively spurred for the industry development.

On the other hand, in the case of Chonnam region, they presented a separated bloc vision that information communication, high-tech industry, automobile and trailer would be supported in the proximity of Gwangju, distribution service, information communication, tour-leisure, fine chemistry, automobile, and machine parts in the Gwangyang bloc, and ship building, vessels and fishing related industry in the Mokpo bloc. Furthermore, selecting bio-industry as leading industry for a new generation in Chonnam region, they proceed in making diversified efforts for the success of business.

\section{Prospect on Industrial Structure Enhancement Policy in Gwangju- Chonnam Region}

Wrapping up the previous discussions in the development history in GwangjuChonnam region, this section suggests four policy recommendations on the industrial structure enhancement policy, in particular, focusing on GwangjuChonnam region. First, the improvement of business environments is necessary. The task to increase regional economic level and thus residents' income level by the industrial structure enhancement should be taken considerbly. The basic 
principle for this purpose is to construct business-friendly environments. Then, it is necessary to establish SOC(Social Overhead Capital). As lack of SOC can cause discrimination in use and thus different economic rent, secure and sufficient amount of SOC should be supplied. In establishing SOC, not only hardware infrastructures such as roads, ports, airports, and distribution related facilities, but also software infrastructures such as administration, finance, communication, trade, customs, laws, and information provision should be sufficiently built.

In particular, institutional regulations related business and economic activities should be drastically removed. Local regulations to protect regional companies should be largely reduced and fair applications of general regulation over both existing companies and new comers should be applied so that efficient companies which have competitiveness can enjoy more profits. Removing invisible local barriers and entry barriers can be realized by supplying high quality infrastructure to new companies equally. If a company can run a business transparently regardless of its political and regional backgrounds, only economic factors would be considered to determine its best location.

Second, it is helpful to induce a built-up-type of large scale company in early development phase of new industry. Although the location choice of high-tech industry is relatively free from regional limitation, a successful business is developed in a place where information and knowledge are concentrated. As an example, Silicon Valley in the US can succeed with the benefits from the proximity of Stanford University and San Francisco. The trend will be more remarked in South Korea in which information, capital, and human resources are highly concentrated in Seoul. Key factors of knowledge industry, such as technology development, planning, and strategic management, can provide multiple benefits of advantages and synergy effects in the physically clustering area. Therefore, it is reasonable for the region rich in land and pleasant nature to take a role of assembling developed products.

Although high-tech optical electronics and bio-industry are selected as specialized industries and a special industrial complex to support these industries are built in Gwangju-Chonnam region, it is hard to have a success as it is because they have a little base of manufacturing companies for high-tech industry. To increase the efficacy of the special promotion policy, benefits more than general movement costs should be expected for corporations to move-into this region. They should provide SOC and land resources in the region as a base for production and assembly as well. These policies will cause a big cost.

Furthermore, considering resource status in the region such as lack of human resources with modern management, the realization of promoting regional 
economy through fostering small business and venture business is evaluated very low. To increase this possibility, companies which assemble and process a product with a bigger linkage effect should be given priority, even though they are not much involved in high-tech industry. Although high-tech and non-pollution industries are preferred as a standard for specialized industry for the region, they should not adhere to high-tech industry development in the early development phase. Business opportunities should be given to companies involving in processing and assembling but entailing some extent of hardware, in combination with being in the specialized industry group. Too much dependence on the highend image of high-tech industry, which might give positive demonstration effects of local governments, has a risk to be left eventually as an empty shell.

Rather, as a slow-up policy, continuous interests and support on the renovation of the existing industry are required. Through advancing the existing industries, profit accumulation in material resources, fostering human resources with managerial ability, and transition of regional emotion toward economy-oriented mind can be generated. After that phase, endogenous development of the high-tech industry can be possible in late development phase.

Third, the improvement of the existing specialized industry is important. Renovation of matured industry and encouragement of the linkage effect will not only promote regional economy and residents' income level, but also provide physical base to develop the high-tech industry in the next phase. The important factor to be considered in selecting a specialized industry is that it should have a bigger potential of growth to have more linkage effects in the region. It should also be a big assembly industry which has large forward and backward production inducement effect in the region.

For example, in the case of Gwangju region, although the automobile and consumer electronics industries are matured and declining in the national economy in part, they have still significant effect in this region. Grocery industries, chemical, and machine industries are also necessary in the new economy of knowledge and information. If the past management system is renovated and old technology is advanced in those industries, competitiveness can be acquired. In the case of Chonnam region, petrochemical complex in equipment type can be transformed into a fine chemistry or bio engineering complex to make an organizational relationship with them. Also, cost advantage in metal processing and machine engineering is possible by using geographical proximity to the area of steel production. Mechatronics can be developed in Gwangju by connecting electronic industry and high-tech sensor industry with machine industry. In addition, knowledge-based industrialization can be sought through modernization in fishery and agriculture industry, breaking traditional production method. 
In renovating the existing and matured industries, instead of initiating another special large-scale project, improvement of institutional process in encouraging business transition, facilitating new entry, and supplying land, capital, and quality human resources with management capability is important.

Finally, preparation for living environment is necessary. In selecting specialized industry among industries which have newly highlights or large growth potential, qualitative factors are significantly considered. In these factors, distributional logistic conditions, supply possibility of production factors, and familiarity with regional residents are included. However, the most important factor is the supply of human resources for competitiveness in the long-term period, which can be a core of viability in business.

In supplying human resources, whether high quality human resources have a will to settle in a certain region is the most critical. As we know that the income level of residents is a more reasonable standard than regional production scale, whether high quality human resources want to stay in the region is more important than whether how many high quality human resources are produced in this region. In other words, listing the number of graduate researchers or the number of research schools might underestimate the qualitative side of human resources. Therefore, when local government wants to cluster high-tech industries, even though the scale is not as much as national project level, a basic infrastructure of the plan should be almost equivalent to the national business level.

\section{Conclusion}

This study has two-folded, the retrospect and prospect on regional industrial enhancement policies in Gwangju-Chonnam region. We first examine historic change in industrial structure policies related to regional specialized industry in Gwangju-Chonnam region. We then provide policy suggestions to advance regional industrial structure in the next century. We will now provide the conclusion of the analysis.

From the late $1960 \mathrm{~s}$, the industries chosen as specialized industries for Chonnam region are the petrochemical and the first metal industries, and for Gwnagju region the other mechanical and rubber manufacturing industries, which are known not to stimulate successively other related industries in the region. Most of them are taken by their respective big-sized firms, the location of which has been decided by the central government.

After Asian financial (foreign currency) crisis in the late 1990s, Gwangju and Chonnam provincial governments have chosen optical photonics and bio-related industries, respectively, as their strategic target industries, which will be supposed 
to stimulate other businesses through the regions. Firms doing business in the industries would get financial and administrative supports and tax breaks by the local governments.

But there are some drawbacks. First, there is no plan for encouraging the high educated people to stay in the region, which is a vital factor to make the plan successful. Second, the plans are focused on supporting venture firms, which will be competitive in the future, but don't have any strategy to lure big-sized firms. But the path has too long way to go, in comparison to locating big-sized firms. Cheap land and clean environments are the factors those big-sized firms are searching for in the country-side area to set up their manufacturing or assembling plants. Therefore the local governments should pay more efforts to attract big-sized manufacturing firms. Third, there is no mention in the plan about the renovation of the well-established industries. The traditional industries can be transformed to high-tech industries with some proper renovation of production process or change of management, which will be profitable in the near future. Therefore these industries deserve to get renovated in the transition to brand new high-tech industries.

Finally, we will point out some key factors to be considered for global competition in the 21 st century. In particular, the emergence of late developing countries, deindustrialization in manufacturing and post-industrialism, and growth gap between old and new industries will give a significant impact on the future industrial policies. First, as intensively promoted industries in late developing countries such as China and India are in competition with major domestic major industries, the emergence of developing countries is a threat to domestic industries. Second, negative effects on domestic industrial structure are caused by hollowing out phenomena in manufacturing industries, deindustrialization. They are attributed to the factors such as increased price of production factors, lack of labor due to evasion of manufacturing, intensive price competition in middle and low priced market with developing countries, and fast movement of domestic companies toward high value added industry. Finally, growth gap between old and new industries generates several gaps between companies in production, between employments, between income level, which in return generates gap between technological innovation (in education and investment on human resources), which constitutes a vicious circle to expand the growth gap between industries. This will trigger the instability of domestic industrial structure.

As a response to this trend, stabilization of the international industrial structure is ideally required by constituting division of labors and industries on the global level. However, practically, each country recognizes that the reorganization of domestic industrial structure based on a new growth engine industry should be developed 
from the individual country perspective. Thus, there is a prisoner's dilemma in that international coordination and cooperation are difficult due to differential competition between developing and developed countries which seek their own interests. It will definitely call for the global cooperation for solving global imbalance. Therefore, on the one hand, from the perspective of individual government, not only constant promoting the renovation of regional industrial structure based on the traditional industries, but also seeking for a new growth industry engine to escape catching up policy by late developing countries. On the other hand, there should be coordination and cooperation between different policies in individual governments. In particular, creatively well-designed dual policy for competition and cooperation by local governments in Gwangju-Chonnam region should be established and continuously implemented.

\section{REFERENCES}

Cho, J.Y. (1985).The study of the project components and impact analysis of Gwangju regional projects. The Studies in Regional Development, 17(1), 1-38.

Cooke, P. and Morgan, K. (1998). The associational economy: Firms, regions and innovation. Oxford University Press.

Freeman, C. (1982). The economics of industrial innovation. Francis Pinter, London.

Gwangju-Chonnam Development Institute (GCDI). (1998). Development Master Plan, GCDI.

Jin, Y.H. (1990). A small study on choosing strategic industries for high-tech industrial estate. The Studies in Regional Development, 22(1), 67-92.

Krugman, J.R. and Melvin, J.R. (1998). The theory of international trade. Harper \& Row, New York.

Lee, J.K. (1990). High-tech industry and regional economy. The Studies in Regional Development, 22(1), 33-42.

Lee, J.K. (1998). Development strategies and characteristics of tourism industry in Gwangju and Chonnam province. The Studies in Regional Development, 30(1), 161-190.

Lee, S.H. (2000). Cooperative strategies between pioneering knowledge industry and preexistence industry for the advancement of industry structure in Gwangju. Gwangju Economy Study, 13, Gwangju City. 
Lee, S.H. (2002). Regional policy for science and technology innovation system. The Studies in Regional Development.

Lim, H.S. (1993). A study on the regional specialized industries. The Studies in Regional Development, 28(1), 155-182.

Lundvall, B. A. (1992). National systems of innovation: Towards a theory of innovation and interactive learning. Printer Publishers, London,

Min, J.S. (1970). Strategy of community development. The Studies in Regional Development, 2(1), 1-21.

Min, J.S. and Park, K.S. (1974). Basic strategy of economic development in Honam province. The Studies in Regional Development, 6(2), 1-62.

Park, K.S. (1970). An analysis of regional structures in Korean industry: focused on the trend derived from 1960 to 1966. The Studies in Regional Development, 2(1), 121-148.

Park, K.S. (1984). An analysis of structural characteristics of Gwangju economy. The Studies in Regional Development, 16(1)

Porter, M. (1996). Competitive advantage, agglomeration, economies and regional policy," International Regional Science Review, 19, 85-94.

Porter, M. (1998). Clusters and the new economy of competition. Harvard Business Review, 77-90.

SERI (1995). Local government and regional special industry.

SERI (1996). The analysis on the specialized industry of gwangju and jeonnam area, SERI.

Sohn, Y.Y. (1995). Foreign economic policy of Gwangju-Chonnam local governments for economic cooperation in the yellow sea area. The Studies in Regional Development, 27(1), 1-26.

Sohn, Y.Y. (1997). The role of local government in economic development policy; In the case of Korea, Japan, China, and Southeast Asian countries, The Studies in Regional Development, 29(1), 173-184.

Sohn, Y.Y. (2000). Retrospects and suggestions for industrial structure policy of Gwangju-Chonnam. The Studies in Regional Development, 32(1),111-131. 